and relations of the organs disturbed by its size and structure; but eventually no doubt remained in our minds that the seat of the disease was the right ovary. The colon, especially the ascending portion, was much enlarged; it could be traced down, still much distended, to the commencement of the sigmoid flexure, where all traces of its structure were lost, and its calibre entirely obliterated by a growth of similar character to that of the ovary, but much denser and smaller. In front, the mass thus formed was crossed by a firm rounded band, which tied it tightly down to the neighbouring vessels. The uterus and left ovary were easily distinguishable, and quite healthy. The trocar was found to have punctured the cacum in the widest and most prominent part; the gut itself was quite healthy, the opening patent, and the connexion between the mucous membrane and the skin precisely like that which occurs in other sinilar positions. There were no marks of in. flanmation or injury, except the firm old adhesions which had glned the surface of the gut to the abdominul parietes: in fact, nothing could look more natural and free from disease than the new opening and surrounding parts.

Remarks. It would seem that the first link in the chain of diseased actions was the disease of the ovary, which, by its growth, cither directly or through the medium of the ligamentous baul, pressed upon and partially obstructed the calibre of the gut. The increase of the ovary caused pro. gressive interference with the intestine, and, eventually, total occlusion; which could not, however, have been so close at the time of operation as it was afterwards found to be, as it then allowed freely the passage of the long tube, and of rery bulky injections. But there can now be no doubt that the sigmoid flex ure was the seat of the obstruction, and that Amussat's or Callisen's operation would have been admissible so far as regards the mere relief of the distended bowel. Probably the bowels had lost their expulsive power from over distension; and hence no frecal matter or gas passed, though the stricture was sufficiently imperfect to admit the tube. The further progress of the case is due to the development of the cancerous masses, and to their mechanicul effects on the neighbouring parts, but chiefly to the general effect of the disease in lowering and extinguishing the powers of life.

The practical object of making this statement is to point out that the operation performed was in itself perfectly successful; it at once and perfectly evacuated the canal, and restored the patient from imminent death; it produced no local ill effect; it answerel its purpose for eighteen months, and might, as far as appears, have continued to do so to any period to which life might have been prolonged. The development of maliguant discase, however, premiturely closed the scene.

\section{ENLARGEMENT OF THE TONSIL AND UVULA, IN RELATION TO DEAFNESS.}

By W. C. Wilinarson, F.R.S., Surgeon to the Manchester Institution for Diseases of the Ear; Consulting Surgeon to the Chorlton-upon-Medlock Dispensary ; and Professor of Anatomy and Physiology in Owen's College, Manchester.

[Reall Urfore the Lancashire and Cheshire Branch, June 2.1th, 185\%.]

There are some forms of disease which have hitherto defied all known remedial agents; hence, on the alleged discovery of specifics capable of arresting their progress, the profession is usually prepared to give each new remelly a fair triul. But such trials are too often indiscriminately made. The fact being known that benefit has been derived in a given disease from some new plan of treatment, the latter is often resorted to with little reference to the peculiarities of the case; failures are frequent, and the new appliance falls into unmerited disuse.

Such epidemic recourse to new curative agents is not unknown in aural surgery. Oil of almonds, glycerine, syringing, and tonsil-cutting have had their turn, and with equally slight reference to the pathological causes of deafness in the cases to which they were applied. The real value and operation of the last of these methods of treatment is the subject into which I propose to inquire this morning.

When the cxcision of enlarged tonsils, for the cure of deaf ness, was first suggested, the treatment did not appcar unpromising to men superficially acquainted with the anatomy of the throat. Under a vague impression that the orifice of the Eustachian tube was located somewhere behind the tonsil, it appeared not improbable that the former might be so compressed by the latter, when abnormally enlarged, as to impede the free entrance of air into the tympanic cavity. But a more accurate knowledge of the anatomy of the throat renders the impossibility of such interference obvious, as both $\mathrm{Mr}$. Ha vey and Mr. Wilde have so properly pointed out. At the same time we must guard against the opposite error of considering that enlarged tonsils in no way interfere with tho hearing, or that their partial excision is a useless operation. How and to what extent do they exercise such an influence? A correct answer to this query will guide us to sound and beneficial practice.

Every surgeon familiar with cases of deafness is aware how many of them originate in cuturrhal attacks. Orilinary catarrhal inflammation of the mucous membrane of the throat; spreading in various directions, frequently extends along the Eustachian tube, and enters the cavity of the tympanum. Having reached this confined cavity, it soon ettects injurious changes in the contiguous solt tissues, which not unfrequently extend to the surrounding osseous structures, especially in strumous subjects, or after attacks of scarlatina. In the class of cases to which I have now referred, irritation of the mucous membrane of the throat and nares is the primury cause of the aural disease; but whatever teuds to perpetuate such irritation, indirectly increases the mischief in the eur.

Fnlarged tonsils and uvilse are equally sources of pharyngeal irritation; hence they often require to be reduced to normal dimensions before much improvement can be elfected in the impaired auditory function. If this cannot be effected by improving the general health combined with the topical application of astringent remedies to the throat, recourse must be had to excision. I need not remind a medical tudience how much enlurged tonsils predispose to ulceration of the throut. The frequent recurrence of such attacks is sometimes regurded as indicative of a defective constitution; whereas neglected hypertrophy of the glands in question is often the local and sole cause of the mischief. But repeated accessions either of ulceration or enlargement of the tonsils, rarely occur without occasioning more or less of deafness : hence the necessity for a prompt removal of what may so soon prove the exciting cause of serious aural disease. The following case illustrates the opinions just uttered.

CASE I. E. B., a girl 15 years of age, consulted me early in June 1856. She had frequently suffered from catarrhs, accom. panied by ulcerated tonsils; and when I first saw her the tonsils were large, the velum and uvula were much relaxed, and the voice presented the thick, non-resonant character so often noticed in these cuses. The Eustachiun tubes were closed, and the distance at which the tick of my watch could be heard was one inch on the right side and three on the left : the former being the side on which the tonsil was most enlarged. The use of astringent gargles and of the Eustachian catheter so far ameliorated the girl's deafness, that, by the beginning of August, the hearing distance on the right side was from twelve to fourteen, and o:1 the left fully fifteen, inches, but beyond this we failed to make any progress. On Augilst 1:2th, I removed the right or largest tonsil; and by the !th of the fol. lowing September so comparatively rapid had been her improvement, I found the hearing distance on both sides increased to twenty-four inches; and on October 2 , she was discharged cured. But, having only removed one of the hypertrophied glands, I was not surprised to see her return early in iI areh of the present year, with a recurrence of the deafness. I endeavoured for some time to remove it by means of astringent gargles and the Eustachian catheter; but we male: little progress until March 27 th, when I removed the other tonsil, and beneficial results ensued so quickly that in ten days afterwards she was discharged cured, and has continued well up to the present time.

The following case illustrates my statement, that precisely similar conditions result from an enlarged uvula, and its remoral.

CASE 1I. MI. B., a Spanish merchant, first consulted me early in April last. He had been deaf, in varying degrees, during eight years, the affection becoming worse each winter, as well as during any accession of eatarrh. When I first saw him, he could only hear my watch when in direct contact with his right ear, and at the distance of one inch from the left. I tried the effect of astringent gargles and the Iiustachian catheter for some days, without producing much improvement; the hearing distance being only prolonged on the right side to two inches, and on the left to four. On April 15th I removed the excess of uvula; and on the 22nd of the same month the heariug distance on the right side was prolonged to two feet, and within a month from that time he was perfectly cured. 
But whilst I recommend the prompt removal of any excess of tonsil or of uvula, let it not be inferred that I regard the operation as a specific for the cure of any form of deafness, or, indeed, one of frequent applicability. The proportion of cases in which enlarged tonsils exist is very small. Mr.Wilde, in his published table of 200 cases of ear disease (Practical Observations on Aural Surgery, p. 114), records only five examples of enlarged tonsils. In my own practice, the proportion of cases in which this symptom was present has been much larger. Of 300 cases of deafness, I found enlarged tonsils in 29, and relaxed and enlarged uvulæ in 57 instances; the former thus occurring in 92 , and the latter in 19 per cent., - a proportion which the humid climate of the district around Manchester will probably explain.

Whilst, as I have just suggested, the numerical proportion of cases of deafness, accompanied by enlarged tonsils, is too small for their excision to be regarded as a remedy of wide applicability, it is equally true that, even where they do exist, their removal not unfrequently fails to be followed by any improvement of the hearing power; on the other hand, I have had some cases in which, though enlarged tonsils were present, astringent applications to the throat, and the use of the catheter effected a complete cure, without my resorting to excision of the glands, which still continued enlarged. I should anticipate some future recurrence of the deafness in these latter instances; but meanwhile they illustrate my observation, that the mischief does not result merely from the enlargement of the organ, but from the concomitant, and often resultant, state of the surrounding mucous membrane.

I have not seen any cases like those quoted by my friend Mr. Harvey, where excision of the tonsil is affirmed to have further impaired the defective sense. That it has sometimes failed to do good, even when the enlarged gland had obviously co-operated in causing the mischief, is a fact easy of explanation, when we remember how soon irritation of the tympanic cavity, however originated, may be followed by structural changes, which are wholly incurable. The time for applying the remedy has been delayed too long. Such cases of failure only demonstrate the necessity for prompt attention to all irritations of the throat, especially such as threaten to be chronic, without waiting until the hearing faculty is impaired. I too frequently find that when the diminished power has become so obvious as to force itself upon the patient's attention, the time for successful action has gone by.

After the removal of all local causes of irritation has been effected by the means already referred to, aided occasionally by counterirritation, and even local depletion, the Eustachian catheter becomes a valuable adjunct to other remedial appliances. My experience has satisfied me, that on the continent this instrument is employed with unnecessary frequency; but our English practitioners are, perhaps, in some danger of falling into an opposite error, from a desire to avoid an abuse which savours of empiricism. I am convinced that the Eustachian catheter is an instrument of the greatest value. There appears to exist in many professional men an undefined dread of its use ; but I am convinced that this is a groundless fear. I am certain that, in ordinarily skilful hands, the operation is not half so hazardous as catheterism of the urethra. Indeed, it is difficult to imagine what real evil Eustachian catheterism can inflict. The utmost mischief that I have seen it do, has been in two or three cases, where it has occasioned slight in flation of the areolar tissue of the throat with air,-an inconvenience of which nature in a very few hours effects the removal.

Though cases occasionally present themselves in which the deafness passes away, under appropriate treatment, in spite of the enlarged tonsil, there always remains great liability to recurrence of the evil, unless excision is resorted to.

The Dwellings of the Poor. The Earl of Shaftesbury's Bill for the prevention of over-crowding in the dwellings of the poor has been brought down from the House of Lords for the assent of the Lower House of Parliament. The Bill enacts that no house or part of a house shall be exempted from the provisions of the Common Lodging House Acts by reason only that the lodgers in such house are members of the same family, unless such family consists solely of persons in the relationship of grandfather, grandmother, father, mother, child or children, grandchild or grandchildren; and the onus probandi as regards relationship will lie on the persons prosecuted at the instance of the police. The Commissioners of Police are empowered to enforce the 29th section of the Nuisances Removal Act. The Act will only apply to such parts of the metropolis as are situate within the metropolitan police district.

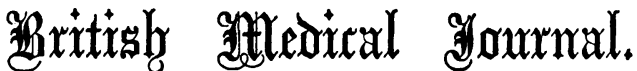

\author{
SATURDAY, AUGUST 8TH, 1857.

\section{THE ANNUAL MEETING OF THE} \\ A S S O C I A T I ON.
}

THE Twenty-fifth Anniversary of the Association, which has just been celebrated at Nottingham, was a notable gathering, for many reasons. It was the first meeting since the inauguration of the new system of self-government. The old selfappointed Council gave up their power, at the Birmingham meeting last year, to the new one elected by the Branches,the close vestry, if we may so term it, which was perhaps ne. cessary to keep the Association right in its youthful days, gave place, on that occasion, to the free parliament elected by universal suffrage. The new system has thus had one year of trial; and the second representative Council of the Association came into office, at Nottingham, with the new President. On comparing the names of the representatives for the two years, as well as those of the two Committees of Council, it will be seen that a fair amount of new blood has been introduced; while anything like an entire change has been judiciously avoided. Thus our parliament and our ministry are suffciently new, and (what is mostimportant) they are responsible for their acts to the general body of the Associates. We have no doubt whatever that the infusion of new blood, and the adoption of more liberal principles, will act well for the Association during the ensuing year; and that our "great and glorious" meeting at Edinburgh in 1858 , (for so by anticipation we venture to term it) will serve to prove that the Association, as it has grown in strength and stability, has also advanced in the art of self-government.

As regards the Meeting, the proceedings of which will be found fully reported in another column, we can speak with satisfaction. The numbers were respectable, and the tone which animated the meeting was admirable. Many of our kind friends. who delight to see the Association in hot water, predicted a stormy discussion at the General Meeting with respect to the manner in which the Medical Reform Committee had discharged their extremely delicate and arduous duty during the past year, the most momentous one within the recollection of the Associates with respect to Medical Reform. But they were doomed to disappointment. The fresh breeze which prevailed during the discussion was a healthy one; and, although some hostile criticisms were heard, yet the vast majority of the meeting fully approved of the manner in which the Committee acted under most trying circumstances.

Mr. Headlam's Bill was as clearly the Bill of the Association in the Assembly Room at Nottingham, as it was at the various Branch meetings where petitions in its favour were so unanimously drawn up. But we suppose we must speak of $\mathrm{Mr}$. Headlam's Bill no longer, since the Government have determined to build upon its ruins, not by the appointment of a royal commission, but by the more direct method of putting the matter into the hands of Mr. Cowper, whose letter inviting Sir Charles Hastings to a conference upon the matter must be taken, we trust, as a proof that the Government, in the ma- 